\title{
Struktur Kandelia candel (L.) Druce di Pulau Payung Sungsang, Banyuasin, Sumatera Selatan
}

\author{
(Struktur Kandelia candel (L.) Druce di Pulau Payung Sungsang, Banyuasin, \\ Sumatera Selatan) \\ Sarno ${ }^{1 *}$, Hanifa Marisa ${ }^{1}$, \& Fadilla Surya Army ${ }^{1}$ \\ 1Jurusan Biologi, Fakultas Matematika dan Ilmu Pengetahuan Alam, Universitas Sriwijaya \\ Inderalaya Ogan Ilir 30662 \\ *Email : sarno_klaten65@yahoo.co.id
}

\begin{abstract}
Mangroves have a certain vegetation composition, forming these vegetation groups are various species of mangrove plants such as mangrove forests as forests that grow more in alluvial mud in coastal areas and river mouths that function tides. Indonesia there are 14 types of rare mangrove, one of them is K. candel (L.) Druce. K. candel including one of the mangroves whose status is globally scarce and needs special management. The purpose of this study was to determine the structure of habitat vegetation and abundance of K. candel on Payung Island, Sungsang District, Banyuasin, South Sumatra. Determination of the station and the transect point of the study using the method of purposive sampling was conducted using the line transect method, obtained 5 observation stations with each station consisting of the transect line. Based on the results of the study, found 13 species from 8 families divided into categories of mangrove, minor and associate mayors. Habitat for K. candel on Payung Island found at station 2 with salinity $0 \%$ and substrate throwing type. K. candel is also found at station 4 with salinity $0 \%$ and type sandy substrate toss. The dominant vegetation on Payung Island is A. alba seen from NP at the tree level of $77.77 \%$, the stake level is A. alba with NP of $86.67 \%$, and at seedling level, namely A. alba by $65.52 \%$. The significance value of K. candel at the tree level is $30.59 \%$, the sapling level is $47.33 \%$ and at the seedling level of $24.48 \%$ it shows the abundance of K.cande is limited.

KEYWORDS : mangroves, vegetation, Kandelia cande, Payung Island
\end{abstract}

\section{INTISARI}

Mangrove mempunyai komposisi vegetasi tertentu, pembentuk kelompok vegetasi ini adalah berbagai spesies tumbuhan mangrove seperti hutan mangrove sebagai hutan yang terutama tumbuh pada tanah lumpur aluvial di daerah pantai dan muara sungai yang dipengaruhi pasang surut air laut. Indonesia terdapat 14 jenis mangrove langka salah satunya K. candel (L.) Druce. K. candel termasuk salah satu mangrove yang statusnya langka secara global dan perlu dilakukan pengelolaan secara khusus. Tujuan penelitian ini yaitu untuk mengetahahui struktur vegetasi habitat dan kelimpahan K. candel di Pulau Payung, Kecamatan Sungsang, Banyuasin Sumatera Selatan. Penentuan stasiun dan titik transek penelitian menggunakan metode purposive sampling sampling dilakukan dengan menggunakan metode line transect, ditentukan 5 stasiun pengamatan, masing-masing stasiun pengamatan meliputi tiga garis transek. Hasil penelitian menunjukkan bahwa dijumpai 13 spesies dari 8 famili yang terbagi dalam kategori mangrove mayor, minor dan asosiasi. Habitat K. candel di Pulau Payung ditemukan pada stasiun pengamatan 2 dengan salinitas $0 \%$ dan tipe substrat lempung. $K$. candel juga dijumpai pada stasiun pengamatan 4 dengan salinitas $0 \%$ dan tipe substrat lempung berpasir. Vegetasi yang mendominasi di Pulau Payung yaitu jenis A.alba BI. dilihat dari NP pada tingkat pohon sebesar 77,77\%, tingkat pancang yaitu A. alba dengan NP sebesar $86,67 \%$, dan pada tingkat semai yaitu jenis A. alba sebesar $65,52 \%$. Nilai penting K. cande pada tingkat pohon sebesar $30,59 \%$, tingkat pancang sebesar $47,33 \%$ dan pada tingkat semai sebesar 24,48\% ini menunjukkan bahwa kelimpahan dari K. candel terbatas.

KEYWORDS : mangrove, vegetasi, . Kandelia candel, Pulau Payung 
Struktur Kandelia candel (L.) Druce di Pulau Payung Sungsang, Banyuasin, Sumatera Selatan (Sarno, Hanifa Marisa, \& Fadilla Surya Army)

\section{PENDAHULUAN}

Indonesia memiliki luas mangrove $3.112,989$ ha atau $22,6 \%$ berdasarkan total luas mangrove yang ada di dunia (Mauludin et al. 2018). Mangrove terluas terdapat di Papua sekitar 1.350.600 ha (38\%), Kalimantan 978.200 ha (28\%) dan Sumatera 673.300 ha (19\%). Hutan mangrove tumbuh berbatasan dengan darat sehingga ekosistem ini merupakan daerah transisi yang tentunya dipengaruhi oleh faktor-faktor lingkungan seperti salinitas, $\mathrm{pH}$, jenis substrat dan pasang surut (Pramudji, 2000). Mangrove mempunyai komposisi vegetasi tertentu. Pembentuk kelompok vegetasi ini adalah berbagai spesies tumbuhan mangrove seperti hutan mangrove sebagai hutan yang terutama tumbuh pada tanah lumpur aluvial di daerah pantai dan muara sungai yang dipengaruhi pasang surut air laut (Noor et al. 2012). Mangrove dapat beradaptasi secara fisiologis terhadap lingkungan yang khas, yaitu salinitas tinggi, sedang atau rendah, tipe tanah yang didominasi lumpur, pasir atau lumpur berpasir, dan terpengaruh pasang surut sehingga terbentuk zonasi. Tiap lokasi mangrove mempunyai keanekaragaman vegetasi yang berbeda, bergantung pada umur mangrove tersebut (Suwignyo et al. 2009).

Pulau Payung merupakan sebuah pulau yang terletak di muara Sungai Musi secara administratif berada di Kecamatan Sungsang Kabupaten Banyuasin Provinsi Sumatera Selatan. Pulau Payung merupakan pulau dataran rendah dengan substrat berlumpur yang dipengaruhi oleh pasang surut air laut sehingga tergolong ekosistem esturia atau perairan payau. Salah satu jenis mangrove yang hidup di Pulau Payung yaitu Kandelia candel.

K. candel termasuk salah jenis tumbuhan mangrove yang terletak di zona pesisir pantai. Tumbuhan ini sering dimanfaatkan oleh masyarakat sekitar sebagai kayu bakar. Menurut Duke et al. (2010), status konservsi K. candel secara global diketahui Least concern atau beresiko rendah sehingga tidak menjadi kekhawatiran menuju kepunahan. Distribusi dari K. candel tersebut tersebar di Timur Laut Sumatera, Kalimantan Barat dan Utara, India, Burma, Thailand, Indo Cina, Cina, Taiwan, Jepang Selatan dan Malaysia. Indonesia terdapat 14 jenis mangrove langka dan K. candel termasuk salah satu yang statusnya langka secara global (Noor et al. 2012). K. candel tumbuh baik pada tanah yang bergambut atau rawa air tawar dan dapat tumbuh di daerah perairan payau (Rahman, 2018), sehingga perlu dilakukan pengelolaan secara khusus. Penelitian ini bertujuan untuk mengetahahui struktur vegetasi habitat dan kelimpahan $K$. candel di Pulau Payung, Kecamatan Sungsang, Banyuasin Sumatera Selatan. 


\section{METODE PENELITIAN}

\section{Lokasi Penelitian}

Penelitia ini dilakukan di Pulau Payung, Kecamatan Sungsang, Banyuasin, Sumatera Selatan pada bulan Desember 2019-Februari 2020. Penelitian ini dilakukan di 5 stasiun pengamatan (Gambar 1; Tabel 1).

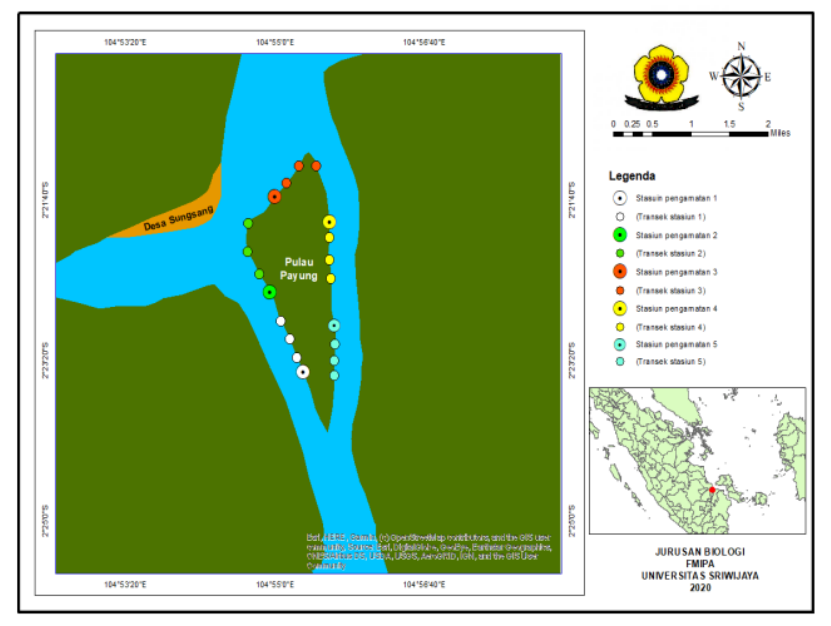

Gambar 1. Peta lokasi penelitian (Arc Map 10.12019 )

Tabel 1. Koordinat geografis transek dilokasi penelitian

\begin{tabular}{|c|c|c|}
\hline Lokasi & Transek & Koordinat Geografis \\
\hline \multirow[t]{3}{*}{ Stasiun Pengamatan 1} & 1 & S $02^{\circ} 23^{\prime} 03,38^{\prime \prime}$ E $104^{\circ} 55^{\prime} 07,86^{\prime \prime}$ \\
\hline & 2 & S $02^{\circ} 23^{\prime} 01,52^{\prime \prime}$ E $104^{\circ} 55^{\prime} 07,13^{\prime \prime}$ \\
\hline & 3 & S $02^{\circ} 22^{\prime} 59,31^{\prime \prime}$ E $104^{\circ} 55^{\prime} 05,56^{\prime \prime}$ \\
\hline \multirow[t]{3}{*}{ Stasiun Pengamatan 2} & 1 & 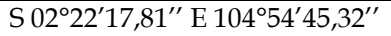 \\
\hline & 2 & S $02^{\circ} 22^{\prime} 20,32^{\prime \prime}$ E $104^{\circ} 54^{\prime} 46,52^{\prime \prime}$ \\
\hline & 3 & S $02^{\circ} 22^{\prime} 23,65^{\prime \prime}$ E $104^{\circ} 54^{\prime} 47,27^{\prime \prime}$ \\
\hline \multirow[t]{3}{*}{ Stasiun Pengamatan 3} & 1 & S $02^{\circ} 21^{\prime} 33,26^{\prime \prime}$ E $104^{\circ} 55^{\prime} 04,69^{\prime \prime}$ \\
\hline & 2 & S $02^{\circ} 21^{\prime} 30,81^{\prime \prime}$ E $104^{\circ} 55^{\prime} 05,96^{\prime \prime}$ \\
\hline & 3 & $\mathrm{~S} 02^{\circ} 21^{\prime} 25,88^{\prime \prime} \mathrm{E} 104^{\circ} 55^{\prime} 09,43^{\prime \prime}$ \\
\hline \multirow[t]{3}{*}{ Stasiun Pengamatan 4} & 1 & 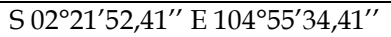 \\
\hline & 2 & S $02^{\circ} 21^{\prime} 49,09^{\prime \prime}$ E $104^{\circ} 55^{\prime} 34,03^{\prime \prime}$ \\
\hline & 3 & S $02^{\circ} 21^{\prime} 47,07^{\prime \prime}$ E $104^{\circ} 55^{\prime} 34,03^{\prime \prime}$ \\
\hline \multirow[t]{3}{*}{ Stasiun Pengamatan 5} & 1 & S $02^{\circ} 22^{\prime} 11,99^{\prime \prime}$ E $104^{\circ} 55^{\prime} 34,38^{\prime \prime}$ \\
\hline & 2 & S $02^{\circ} 22^{\prime} 10,07^{\prime \prime}$ E $104^{\circ} 55^{\prime} 32,06^{\prime \prime}$ \\
\hline & 3 & $\mathrm{~S} 02^{\circ} 22^{\prime} 09,06^{\prime \prime} \mathrm{E} 104^{\circ} 55^{\prime} 33,07^{\prime \prime}$ \\
\hline
\end{tabular}

\section{Alat dan Bahan}

Alat yang digunakan pada pengamatan adalah alat tulis, buku catatan, GPS, jangka sorong, kamera, $\mathrm{pH}$ meter, soil tester dan hendrefractometer, multifunction environtment meter, lux meter. Bahan yang digunakan adalah K. candel. Bahan yang digunakan adalah K. candel dan vegetasi mangrove di Pulau Payung. 
Struktur Kandelia candel (L.) Druce di Pulau Payung Sungsang, Banyuasin, Sumatera Selatan (Sarno, Hanifa Marisa, \& Fadilla Surya Army)

\section{Metode Penelitian}

Penentuan lokasi penelitian menggunakan metode purposive sampling. Sampling dilakukan dengan metode Line Transect (kombinasi antara metode jalur dan garis berpetak), transek ini ditarik tegak lurus dari arah sungai ke arah darat sejauh $100 \mathrm{~m}$ dengan jumlah 5 plot, dengan masing-masing ukuran semai: $2 \mathrm{~m} \times 2 \mathrm{~m}$, diameter $<2 \mathrm{~cm}$, pancang: $5 \mathrm{~m} \times 5 \mathrm{~m}$, diameter $<10$ $\mathrm{cm}$ dan pohon: $10 \mathrm{~m} \times 10 \mathrm{~m}$, diameter $>10 \mathrm{~cm}$.

\section{Analisis Data}

Struktur vegetasi mangrove pada setiap stasiun pengamatan dianalisa secara deskriptif yang meliputi kerapatan relatif, frekuensi relatif, dominasi relatif, Indeks Nilai Penting (INP) dan indeks keanekaragaman.

\section{Frekuensi}

Frekuensi menunjukan kehadiran atau keberadaan suatu jenis dalam suatu komunitas dalam titik sampling. Nilai ini menyatakan penyebaran suatu jenis dalam suatu komunitas (Muller-Dombois \& Ellenberg 1974).

$$
\begin{gathered}
\text { Freekuensi }(\mathrm{F})=\frac{\sum \text { plot ditemukan suatu jenis }}{\sum \text { seluruh plot }} \\
\text { Freekuensi Relatif }(\mathrm{FR})=\frac{\text { FM suatu jenis }}{\sum \text { seluruh jenis }} \times 100 \%
\end{gathered}
$$

Kerapatan

Kerapatan merupakan parameter yanng menunjukan jumlah individu dalam suatu area tertentu atau individu satu jenis per satuan luas. Jenis yang ada di plot dicatat dan dihitung jumlah individu dari masing-masing jenis yang ditemukan per satuan luas (Muller-Dombois \& Ellenberg 1974).

$$
\begin{gathered}
\text { Kerapatan }(\mathrm{K})=\frac{\text { Jumlah Individu }}{\text { Luas Daerah Pengamatan }} \\
\text { Kerapatan Relatif }(\mathrm{KR})=\frac{\text { KM suatu jenis }}{\text { KM Total }} \times 100 \%
\end{gathered}
$$

Dominansi

Dominansi dihitung untuk menggambarkan penutupan suatu jenis tumbuhan pada suatu wilayah. Semakin besar penutupan suatu jenis tumbuhan semakin tinggi nilai dominansinya (Muller-Dombois \& Ellenberg 1974). 


$$
\begin{gathered}
\text { Dominansi }(D)=\frac{\sum \text { BA }}{\text { Luas Daerah Pengamatan }} \\
\text { Dominansi Relatif (DR) }=\frac{\sum \text { DM Suatu jenis }}{\sum \text { DM Seluruh jenis }} \times 100 \%
\end{gathered}
$$

Keterangan: BA (Rata-rata Basal tiap jenis); $B A=\mu r^{2}$

Nilai Penting

Nilai Penting (NP) merupakan hasil penjumlahan parameter kuantitatif relatif (frekuensi, kerapatan dan dominansi), menunjukan parameter ekologi yang signifikan pada distribusi tumbuhan dibandingkan dominan (Muller-Dombois \& Ellenberg 1974).

$$
\mathrm{INP}=\mathrm{KR}+\mathrm{DR}+\mathrm{FR}
$$

\section{Hasil dan Pembahasan}

\section{Komposisi Mangrove di Pulau Payung}

Berdasarkan penelitian yang telah dilakukan pada seluruh stasiun pengamatan, dijumpai 13 jenis mangrove yang termasuk kedalam 8 famili. Jenis vegetasi yang diketahui dapat dikategorikan sebagai jenis mangrove mayor, minor, dan mangrove asosiasi dapat (Tabel 2).

Tabel 2. Jenis-jenis mangrove di Pulau Payung Sungsang, Sumatera Selatan

\begin{tabular}{cllll}
\hline No. & \multicolumn{1}{c}{ Jenis } & \multicolumn{1}{c}{ Nama Lokal } & \multicolumn{1}{c}{ Tipe Mangrove } \\
\hline 1. & Avicennia alba BI. & Api-api & Avicenniaceae & Mayor \\
2 & Avicennia marina (Forsk.) Vierh. & Api-api abang & Avicenniaceae & Mayor \\
3 & Avicennia officinalis L. & Api-api ludat & Avicenniaceae & Mayor \\
4. & Bruguiera parviflora (Roxb.) W.\& A. ex Griff. & Langgade & Rizhophoraceae & Mayor \\
5 & Bruguiera sexangula (Lour.) Poir. & Lindur & Rizhophoraceae & Mayor \\
6 & Rhizophora apiculata BI. & Bakau & Rizhophoraceae & Mayor \\
7 & Kandelia candel (L.) Druce & Berus-berus & Rizhophoraceae & Mayor \\
8. & Sonneratia caseolaris (L.) Engl. & Pedada & Sonneratiaceae & Mayor \\
9. & Nypa fruticans Wurmb. & Nipah & Arecaceae & Mayor \\
10. & Excoecaria agallocha L. & Buta-buta & Euphorbiaceae & Mayor \\
11. & Aegiceras corniculatum (L.) Blanco & Teruntun & Primulaceae & Mayor \\
12. & Acrostichum speciosum Willd. & Paku laut & Pteridaceae & Minor \\
13. & Hibiscus tillaceus L. & Waru & Malvaceae & Asosiasi \\
\hline
\end{tabular}

Tipe mangrove mayor lebih banyak di temukan di Pulau Payung dengan jumlah 11 jenis mangrove, satu jenis mangrove minor dan satu jenis mangrove asosiasi. Famili Rhizophoraceae yang dijumpai di pulau payung lebih banyak dibandingkan dengan famili yang lain, terdapat 4 jenis yang termasuk famili dari Rhizophoraceae. Rhizophoraceae merupakan famili yang umumnya mendominasi hutan-hutan mangrove. Rhizophoraceae merupakan penyusun tipe mangrove sejati yang dapat tumbuh pada tingkat kadar garam yang 
Struktur Kandelia candel (L.) Druce di Pulau Payung Sungsang, Banyuasin, Sumatera Selatan (Sarno, Hanifa Marisa, \& Fadilla Surya Army)

tinggi dan tumbuh pada zona terluar yang berbatasan langsung dengan laut (Rizki \& Leilani 2017). Famili Rhizophoraceae dapat hidup dengan tipe substrat seperti lumpur, liat, dan batu kerikil (Lewerissa et al. 2018).

Tabel 3. Parameter lingkungan di Pulau Payung Sungsang Sumatera Selatan

\begin{tabular}{cccccccc}
\hline No. & $\begin{array}{c}\text { Stasiun } \\
\text { pengamatan }\end{array}$ & $\begin{array}{c}\text { Suhu } \\
\left({ }^{\circ} \mathrm{C}\right)\end{array}$ & $\begin{array}{c}\text { Salinitas } \\
(\%)\end{array}$ & $\mathrm{pH}$ & $\begin{array}{c}\text { Kelembaban } \\
(\%)\end{array}$ & $\begin{array}{c}\text { Intensitas } \\
\text { Cahaya (lux) }\end{array}$ & $\begin{array}{c}\text { Tipe } \\
\text { Substrat }\end{array}$ \\
\hline 1. & I & 28 & 0 & 7,5 & 88,7 & 0,82 & Lempung \\
2. & II & 27 & 0 & 7,0 & 90,1 & 0,28 & Lempung \\
3. & III & 27,2 & 6 & 7,0 & 97,0 & 0,25 & Lempung \\
4. & IV & 27 & 0 & 7,0 & 91,0 & 0,25 & Lempung Berpasir \\
5. & V & 29,3 & 0 & 6 & 82,4 & 0,25 & Lempung \\
6. & VI & 28,5 & 0 & 6 & 87,3 & 0,76 & Lempung \\
\hline
\end{tabular}

SP I didapatkan 4 jenis mangrove yaitu Nypa fruticans, Excoecaria agallocha, Acrostichum speciosum, dan Hibiscus tiliaceus, Nypa fruticans pada stasiun pengamatan 1 cukup rapat sehingga mempunyai kemungkinan tidak tumbuhnya $K$. candel di stasiun pengamatan 1 karena tidak adanya tempat untuk K. candel bersemai. N. fruticans merupakan anggota suku palmae yang tumbuh di sepanjang sungai yang terpengaruh oleh pasang surut air laut dan $N$. fruticans tumbuh rapat berkelompok, membentuk komunitas murni yang luas di sepanjang sungai dekat muara hingga sungai dengan air tawar (Heriyanto et al. 2011) (Gambar 2).
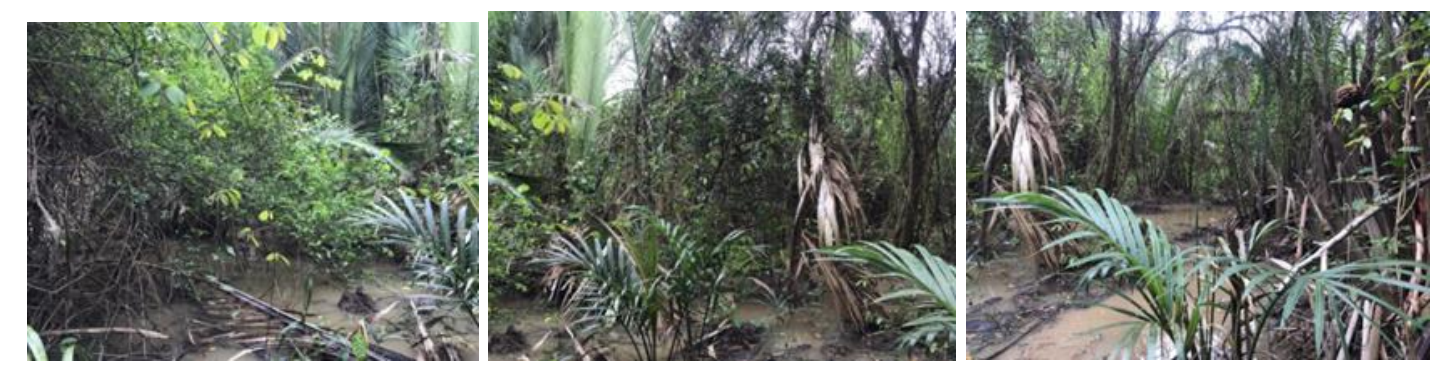

Gambar 2. Kondisi stasiun pengamatanI : (A) Lokasi stasiun pengamatan1 plot; (B) Lokasi stasiun pengamatan 1 plot 5; (C) Lokasi pengamatan stasiun

SP II tedapat 5 jenis yaitu A. alba, K. candel, N. fruticans, S. caseolaris, dan B. parviflora. Vegetasi yang mendominasi di stasiun pengamatan 2 yaitu A. alba dan K. candel (Gambar 5). K. candel tumbuh di perairan air payau yang dipengaruhi oleh pasang surut salinitas merupakan faktor penting dalam pertumbuan tumbuhan mangrove dibandingkan tumbuhan vaskular lainnya. K. candel dapat bertoleransi degan salinitas sedang dan tumbuh subur di lumpur lunak di sepanjang sungai (Rahman, 2018) (Gambar 3). 


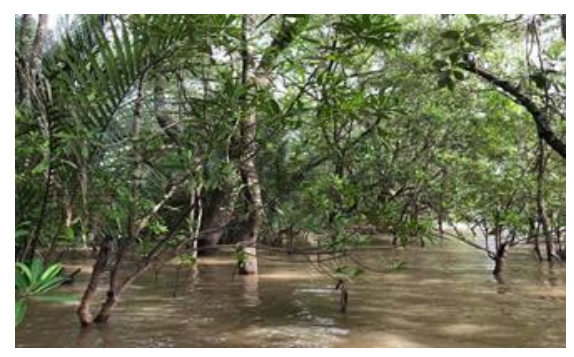

Gambar 3. Lokasi pengamatan stasiun 2

SP3 didapatkan 6 jenis mangrove yaitu A. alba, A. corniculatum, B. parviflora, R. apiculata, $N$. fruticans, E. agallocha. Vegetasi yang mendominasi di stasiun pengamatan 3 ini yaitu A. alba dan A. corniculatum (Gambar 4). SP 3 tidak ditemukan K. candel, dan dilokasi ini memiliki tingkat kelembaban paling tinggi dibandingkan stasiun pengamatan lain dan memiliki tipe substrat lumpur berpasir dan pada SP 3 menjadi salah satu stasiun pengamatan denga salinitas sebesar 6\%o, dikarenakan pada saat pengambilan sampel di stasiun ini sedang pasang sehingga mempengaruhi hasil pengambilan data salinitas dan lokasi SP 3 terletak di bagian hilir yang termasuk bagian muara sehingga pada saat air pasang air laut masuk dan mempengaruhi hasil daru pengukuran salinitas.

Faktor kemungkinan tidak ditemukan $K$. candel karna salah satunya dipengaruhi oleh distribusinya, stasiun pengamatan 3 (Gambar 4) berada lebih dekat kearah laut sehingga pada saat pasang distribusi dari K. candel sulit untuk masuk di stasiun pengamatan 3, dan juga dipengaruhi oleh substratnya karena pada stasiun pengamatan yang ditemukan ada K. candel tidak bersubstrat lumpur berpasir. K. candel tumbuh baik pada tanah yang bergambut atau rawa air tawar dan dapat tumbuh di daerah perairan payau.

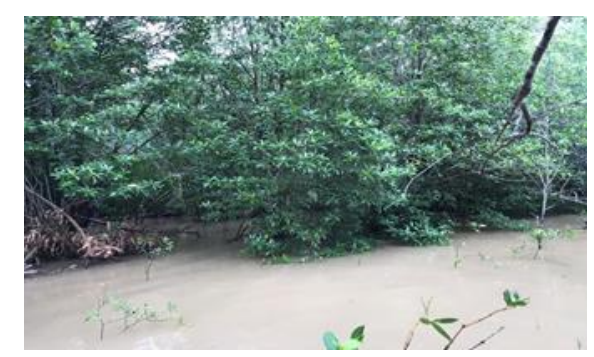

Gambar 4. Lokasi stasiun pengamatan 3

SP 4 sangat mendukung sebagai habitat dari K. candel yang hidup di Pulau Payung (Gambar 5), salah satunya dipengaruhi oleh faktor salinitas, Pulau Payung memiliki Salinitas $\leq$ $0-6 \%$. Perkecambahan K. candel membutuhkan air tawar untuk perkecambahannya, pertumbuhan awal, dan kelangsungan hidup (Rahman, 2018). 


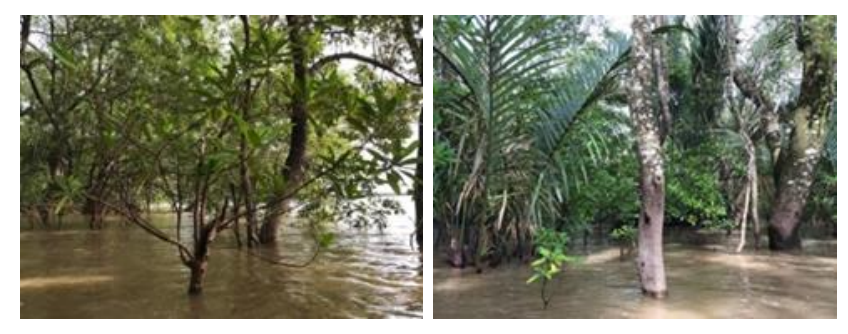

Gambar 5. Lokasi stasiun pengamatan 4 (kiri dan tengah)

Pengamatan di SP 5 didapatkan 7 jenis mangrove yaitu E. agallocha, R. apiculata, A. marina, S. caseolaris, A. officinalis, N. fruticans dan A. speciosum. Vegetasi yang mendominasi di stasiun pengamatan 5 yaitu E. agallocha, S. caseolaris. dan N.fruticans (Gambar 6).

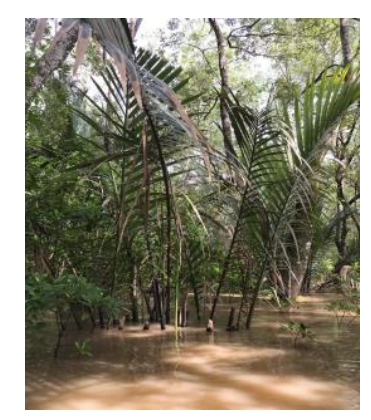

Gambar 6. Lokasi stasiun pengamatan 5

SP 6 tidak dapat diambil data karena vegetasi semuanya $N$. fruticans sehingga tidak memungkinkan untuk dapat menarik transek di stasiun penelitian 6. Kerapatan N. fruticans di stasiun pengamatan 6 sangat mendominasi hampir semua N. fruticans (Gambar 7), sehingga hanya diambil data parameter lingkungan saja sebagai pembanding dengan stasiun pengamatan yang lain. Tipe substrat pada lokasi ini juga berbeda dengan stasiun pengamatan yang lain, di lokasi ini substrat lumpur lebih keras (Tabel 3).

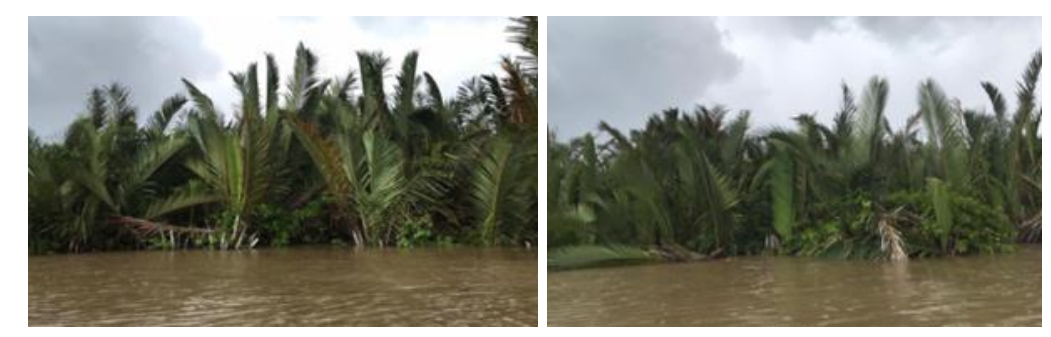

Gambar 7. Lokasi stasiun pengamatan 6 


\section{Struktur Mangrove di Pulau Payung Sungsang Sumatera Selatan}

Berdasarkan identifikasi dan perhitungan yang telah dilakukan pada 5 stasiun pengamatan didapatkan bahwa area stasiun pengamatan memiliki struktur tegakan vegetasi mangrove meliputi 12 jenis pada tingkatan pohon, 11 pada tingkatan pancang dan 10 pada tingkatan semai.

Tabel 4. Tingkat pertumbuhan Mangrove di Pulau Payung Sungsang Sumatera Selatan

\begin{tabular}{|c|c|c|c|c|}
\hline \multirow[t]{2}{*}{ No. } & \multirow[t]{2}{*}{ Jenis Mangrove } & \multicolumn{3}{|c|}{ Nilai Penting (\%) } \\
\hline & & Pohon & Pancang & Semai \\
\hline 1. & Hibiscus tillaceus L. & 6,95 & 19,99 & - \\
\hline 2. & Avicennia officinalis L. & 11,33 & - & - \\
\hline 3. & Bruguiera sexangula (Lour.) Poir. & 14,32 & 8,98 & 2,72 \\
\hline 4. & Aegiceras corniculatum (L.) Blanco & 15,19 & 50,55 & 19,30 \\
\hline 5. & Bruguiera parviflora (Roxb.) W.\& A. ex Griff. & 21,71 & 27,6 & 5,61 \\
\hline 6. & Avicennia marina (Forsk.) Vierh. & 24,74 & - & - \\
\hline 7. & Kandel candel (L.) Druce & 30,59 & 47,33 & 24,48 \\
\hline 8. & Rhizophora apiculata BI. & 32,13 & 8,98 & 3,25 \\
\hline 9. & Excoecaria agallocha $\mathrm{L}$. & 32,82 & 24,57 & 29,44 \\
\hline 10. & Sonneratia caseolaris (L.) Engl. & 32,82 & 17,52 & 7,25 \\
\hline 11. & Avicennia alba BI. & 77,77 & 86,67 & 65,52 \\
\hline 12. & Nypa fruticans Wurmb. & - & - & 65,52 \\
\hline
\end{tabular}

K. candel memiliki NP sebesar 30,59\% lebih kecil dibandingkan dengan A. alba. Faktor yang mempengaruhinya yaitu $K$. candel dapat ditemukan di stasiun pengamatan karena vegetasi habitat di daerah Pulau Payung sendiri cocok dengan K. candel yang dapat hidup di habitat bersubstrat lumpur tetapi dengan salinitas $0 \%$. K. candel termasuk spesies dengan tingkat regenerasi yang lebih rendah. Karena K. candel memiliki tahap perkecambahan yang lama hingga tumbuh tunas (Duke et al. 2010). A. alba dengan tingkat regenerasi yang lebih tinggi karena A. alba memiliki tahap perkecambahan yang cepat. Pertumbuhan K. camdel membutuhkan waktu 2-3 tahun untuk berbunga setelah ditanam, periode berbunga pada bulan November- Desember, masa berbuah bulan Januari- April dan propagul jatuh pada bulan MeiJuni. Berbeda dengan Avicennia yang pertumbuhannya menggunakan perkecambahan yang penyebarannya sangat mudah terbawa arus dan pertumbuhannya cepat (Rahman, 2018).

K. candel di Pulau Payung pada tingkat pancang dapat hidup bedampingan dengan jenis X. granatum, R. apiculata, B. sexangula, S. caseolaris, H. tillaceus, E. agallocha, B. parviflora, K. candel, A. corniculatum dan A. alba. K. candel dapat tumbuh dengan jenis A. officinalis, S. apetala, $X$. granatum, $N$. frutican, dan A. corniculatum yang memiliki habitat yang sama seperti $K$. candel (Rahman, 2018).

K. candel tingkat semai memiliki NP sebesar 24,48\% faktor yang mempengaruhi pertumbuhan semai K. candel lebih sedikit dibandingkan dengan A. alba karena di Pulau 
Struktur Kandelia candel (L.) Druce di Pulau Payung Sungsang, Banyuasin, Sumatera Selatan (Sarno, Hanifa Marisa, \& Fadilla Surya Army)

Payung pohon hanya ada di beberapa tempat saja sehingga untuk persebaran dari K. candel sedikit lebih sulit dibanding A. alba yang pertumbuhannya menggunakan biji yang lebih mudah terbawa arus dan memiliki pohon induk yang banyak di beberapa tempat. Persemaian K. candel dapat hidup dengan tipe substrat tanah liat berlumpur dengan $\mathrm{pH}$ 7,5 dan salinitas $\leq$ 12\%o dengan dipengaruhi pasang surut air laut (Rahman, 2018).

\section{KESIMPULAN}

Struktur vegetasi habitat $K$. candel di Pulau Payung ditemukan pada stasiun pengamatan 2 dengan salinitas $0 \%$ dan tipe substrat lempung. K. candel juga dijumpai pada stasiun pengamatan 4 dengan salinitas $0 \%$ o dan tipe substrat lempung berpasir. Nilai penting $K$. candel pada tingkat pohon sebesar 30,59\%, tingkat pancang sebesar $47,33 \%$ dan pada tingkat semai sebesar $24,48 \%$ ini menunjukkan bahwa kelimpahan dari $K$. candel terbatas atau tidak di setiap stasiun pengamatan terdapat $K$. candel.

\section{UCAPAN TERIMA KASIH}

Terima kasih disampaikan kepada Universitas Sriwijaya melalui dana PNBP tahun 2020 dan ZSL (Zoological Society of London) atas bantuan pembiayaan kegiatan penelitian. Terima kasih juga disampaikan kepada mahasiswa Jurusan Biologi FMIPA Universitas Sriwijaya atas keterlibatannya secara aktif selama kegiatan penelitian berlangsung. 


\section{DAFTAR PUSTAKA}

Duke, N., Kathiresan, K., Salmo III, S.G., Fernando, E.S. Peras, J.R., Sukardjo, S. \& Miyagi, T. Kandelia candel. The IUCN Red List of Threatened Species: 1-9.

Heriyanto, N.M., Subiandono, E. \& Karlina, E. 2011. Potensi dan Sebaran Nipah (Nypa fruticans (Thunb. Wurmb) sebagai Sumberdaya Pangan. Jurnal Pendidikan Hutan dan Konservasi, 8(4): 327-335.

Lewerissa, Y.A., Sangaji, M. \& Latumahina, M.B. 2018. Pengelolaan Mangrove Berdasarkan Tipe Substrat di Perairan Negeri Ihamau Pulau Saparua. Jurnal TRITON, 14(1): 1-9.

Mauludin, M.R., Ria, A. \& Rudhi, P.S. 2018. Komposisi dan Tutupan Kanopi Mangrove di Kawasan Ujung Piring Kabupaten Jepara. Buletin Oseanografi Marina, 7(1): 29-36.

Muller-Dombois, D. \& Ellenberg, H. 1974. Aims and Method of Vegetation Ecology. Canada: John Wiley adn Sons Inc.

Noor, R. Y., Khazali, M. \& Suryadiputra, I.N.N. 2012. Panduan Pengenalan Mangrove di Indonesia. PHKA/WI-IP. Bogor.

Pramudji. 2000. Hutan Mangrove di Indonesia Peranan Permasalahan dan Pengelolaannya. Jurnal Oseana, 25(1): 13-20.

Rahman, Md. M. 2018. Enrichment of Mangrove Ecosystems Through Kandelia candel (L.) Druce Species in the Sundarban Mangrove Forest of Bangladesh. International Journal of Business, Social and Scientific Research, 6(4): 1-8.

Rizki \& Leilani, I. 2017. Etnofarmakologi Tumbuhan Familia Rhizophoraceae oleh Masyarakat di Indonesia. Jurnal Biologi dan Pendidikan Biologi. 3(1): 51-60.

Sukardjo, S. 1984. Ekosistem Mangrove. Jurnal Oseana. 4(4): 102-115.

Suwignyo, R. A., Yakup, P, Munandar, Sarno \& Bagus, H. 2009. Pertumbuhan Awal dan Kemampuan Adaptasi Dua Jenis Mangrove di Muara Sungai Musi Sumatera Selatan. Jurnal Agria., 5(2): 13-21. 